\title{
Effect of Gestational Age on Maternofetal Vascular Function Following Single Maternal Engineered Nanoparticle Exposure
}

\author{
S. B. Fournier ${ }^{1} \cdot$ S. Kallontzi $i^{3} \cdot$ L. Fabris $^{3} \cdot$ C. Love $^{4} \cdot$ P. A. Stapleton ${ }^{1,2}$
}

Published online: 7 February 2019

(c) The Author(s) 2019

\begin{abstract}
Normal pregnancy outcome is accomplished, in part, by rapid and expansive physiological adaptations to the systemic circulation, the extent of which is specific to gestational day (GD) and anatomical location. Pregnancy-related hemodynamic changes in uterine placental blood flow stimulate compensatory vascular signaling and remodeling that begins early and continues throughout gestation. Exposure of the maternal environment to engineered nanomaterials (ENM) during pregnancy has been shown to impact health of the dam, fetus, and adult offspring; however, the consequences of specific temporal (gestational age) and spatial (vascular location) considerations are largely undetermined. We exposed pregnant Sprague-Dawley rats to nano-TiO ${ }_{2}$ aerosols at three critical periods of fetal development (GD 4,12, and 17) to identify vascular perturbations associated with ENM exposure at these developmental milestones. Vascular reactivity of the maternal thoracic aorta, the uterine artery, the umbilical vein, and the fetal thoracic aorta were evaluated using wire myography on GD 20. While impairments were noted at each level of the maternofetal vascular tree and at each exposure day, our results indicate the greatest effects may be identified within the fetal vasculature (umbilical vein and fetal aorta), wherein effects of a single maternal inhalational exposure to nano- $-\mathrm{TiO}_{2}$ on GD 4 modified responses to cholinergic, $\mathrm{NO}$, and $\alpha$-adrenergic signaling.
\end{abstract}

Keywords Nanomaterials $\cdot$ Nanotoxicology $\cdot$ Wire myography $\cdot$ Uterine artery $\cdot$ Umbilical vein $\cdot$ Fetal aorta $\cdot$ Gestational exposure

$\begin{array}{ll}\text { Abbreviations } \\ \text { EDHF } & \text { Endothelium-derived hyperpolarizing factor } \\ \text { ENM } & \text { Engineered nanomaterials } \\ \text { GD } & \text { Gestational day } \\ \mathrm{MAP} & \text { Mean arterial pressure } \\ \mathrm{MCH} & \text { Methacholine } \\ \mathrm{Nano}^{-\mathrm{TiO}_{2}} & \text { Nano-titanium dioxide } \\ \text { PHE } & \text { Phenylephrine }\end{array}$

Handling Editor: Y. James Kang.

P. A. Stapleton

stapleton@eohsi.rutgers.edu

1 Environmental and Occupational Health Sciences Institute, 170 Frelinghuysen Rd, Piscataway, NJ 08854, USA

2 Department of Pharmacology and Toxicology, Ernest Mario School of Pharmacy, Rutgers University, 160 Frelinghuysen Rd, Piscataway, NJ 08854, USA

3 Materials Science and Engineering, Rutgers University, 607 Taylor Rd, Piscataway, NJ 08854, USA

4 Biology and Environmental Studies, Grinnell College, 1116 Eighth Ave, Grinnell, IA 50112, USA
PSS
SNP
UPBF
Physiological saline solution
Sodium nitroprusside
Uteroplacental blood flow

\section{Introduction}

Gestation is characterized by significant physiological adaptations to accommodate the developing fetus. Normal pregnancy outcome is accomplished, in part, by rapid and expansive physiological adaptations to the systemic circulation, the extent of which is specific to gestational day and anatomic location. Pregnancy-related hemodynamic changes in uterine placental blood flow stimulate compensatory vascular signaling and remodeling that begins early and continues throughout gestation [1]. It is well established that disturbances in the maternal and intrauterine environment during gestation can have a long-term impact on fetal health. Common pregnancy complications, including preeclampsia, and intrauterine growth restriction (IUGR) are of vascular origin. Under circumstances of an adverse intrauterine environment, 
the developing fetus is vulnerable to oxygen and nutrient deprivation, impairing fetal growth and development.

Unique material attributes emerge at the nanoscale. Nanomaterials are designed and incorporated with increasing frequency in manufacturing processes, commercial products, and biomedical applications, raising the probability of occupational, environmental and therapeutic exposure. To meet growing consumer demands, the annual global production of nanosized titanium dioxide particles $\left(\right.$ nano- $\left.-\mathrm{TiO}_{2}\right)$ is projected to reach 2.5 million metric tons by 2025 [2]. The pervasive use of ENM raises concerns regarding their safety and potential risks to human health in all life stages.

Evidence from toxicological literature connects engineered nanomaterial (ENM) exposure to adverse cardiovascular endpoints [3-12]. In non-pregnant animals, ENM inhalation leads to impaired coronary [13] and uterine [14] microvascular dysfunction. This blunted hemodynamic response may be impaired for days even after a single exposure [14]. The rapid implementation of ENM and the broad range of current and potential biomedical applications raise concerns about human exposure to ENM during pregnancy and the subsequent risks to maternal and fetal health.

Within a pregnant population this is concerning as significant growth and development occurs at a rapid pace. Early in gestation, the rat blastocyst implants into the uterine endometrium and initiates trophoblast invasion and placental development. If the uterus is non-receptive, implantation can fail. A complete rat embryo is formed on GD 12.5; with respect to cardiovascular formation, septation begins, atrioventricular bundle begins to form, and vasculogenesis is initiated [15]. Pups transition to the first fetal stage on GD 17, wherein cardiovascular maturity is initiated through septal closures, valvular formation, and continued angiogenesis [15]. Perturbation at each of these stages could severely impair fetal health.

We and others have reported evidence to suggest reproductive and developmental toxicities associated with maternal ENM inhalation or instillation; however, the exposure parameters range widely. Our previous studies have focused on early chronic exposures, initiated on GD 4 through GD 19 [16] or single late exposures initiated on GD 19 [14]. Other groups have developed experimental designs wherein repeated exposures occur during developmental milestones [17-19]. Further, differential vascular responses have been reported after a single pulmonary or intravenous maternal exposure near the end of gestation (GD) [17-22]. While there is little homogeneity in these studies, given each group is focused on the maternal toxicity of a different ENM, there is uniformity in that significant implications are reported in maternal and fetal health outcomes.

Together, the inherent complexities of physiological systems may contribute to the differential tissue responses reported with maternal exposure to ENM during pregnancy.
Therefore, the purpose of this study was to identify a potential "critical window" of gestational exposure to ENM on fetal health and provide a macrovascular serial assessment to identify if the greatest vascular dysfunction is of maternal or fetal origin.

\section{Materials and Methods}

\section{Nanomaterial Characterization}

Nano-titanium dioxide (nano- $\mathrm{TiO}_{2}$ ) powder was acquired from Evonik (Aeroxide $\mathrm{TiO}_{2}$, Parsippany, NJ). Previous characterization of this powder has determined the composition to be primarily anatase $(80 \%)$ and rutile $(20 \%) \mathrm{TiO}_{2}$, with a primary particle size of $21 \mathrm{~nm}$ and a surface area of $48.08 \mathrm{mg}^{2} / \mathrm{g}$. Characterization of these particles was re-confirmed via dynamic light scattering (DLS) techniques using Zetasizer Nano ZS by Malvern. The size of the agglomerated nanoparticles in $\mathrm{diH}_{2} \mathrm{O}$ was measured as $231 \pm 21 \mathrm{~nm}$ with Non-Invasive Backscatter optics (NIBS) using a 4-mW, 633$\mathrm{nm}$ laser. $\mathrm{TiO}_{2}$ powder was dried, sieved, and stored under vacuum prior to aerosolization.

\section{Animal Model}

Timed-pregnant Sprague-Dawley (SD) rats were purchased from Charles River Laboratories (Kingston, NY) and allowed ad libitum access to food and water. All animals were randomly assigned to Naïve, Sham, or Exposure groups. Animals in either the Sham or Exposure groups were exposed to filtered air (Sham) or nano- $\mathrm{TiO}_{2}$, respectively, at GD 4, 12, or 17. Animals were euthanized on GD 20. All procedures were approved by the Institutional Animal Care and Use Committee of Rutgers University and were executed in accordance with the standards set forth in the "Guide for the Care and Use of Laboratory Animals" of the National Research Council of the National Academies.

\section{Engineered Nanomaterial Inhalation Exposure}

Animal exposures to nano- $\mathrm{TiO}_{2}$ were performed using a custom rodent inhalation facility designed for whole-body aerosolized nanomaterial inhalation (IEStechno, Morgantown, WV). The collective exposure system consists of a vibrating fluidized bed, a Venturi vacuum pump, cyclone separator, impactor and mixing device, an animal housing chamber, and real-time monitoring devices with feedback control. Nano- $\mathrm{TiO}_{2}$ aerosols were generated via a high-velocity air stream passing through the vibrating fluidized bed and into the Venturi vacuum pump. From there, the aerosols entered the cyclone separator to remove agglomerates greater than $400 \mathrm{~nm}$ at an input flow rate of $60 \mathrm{~L} / \mathrm{min}$ of clean dry air 

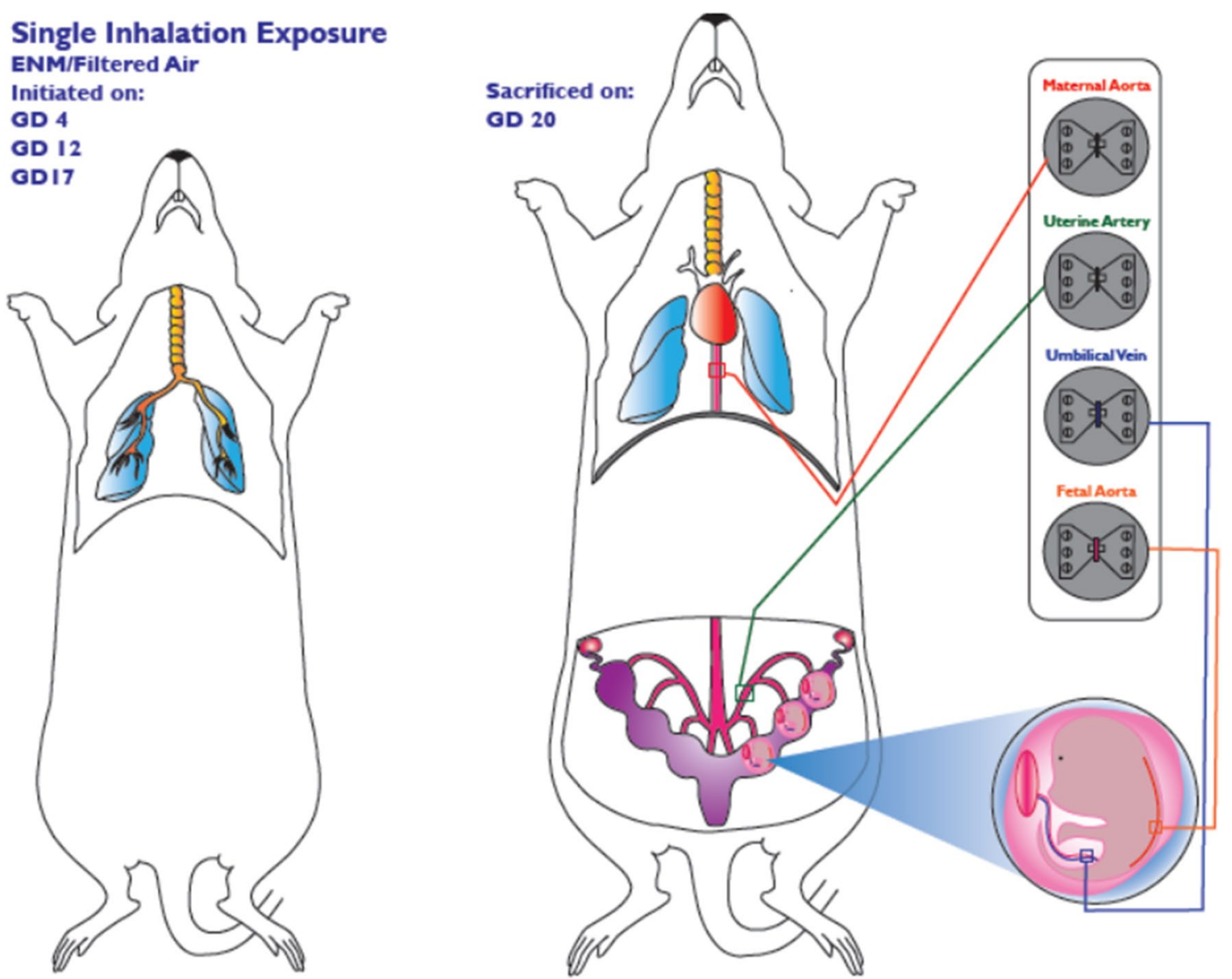

Fig. 1 Experimental design schematic. All animals were sacrificed on GD 20

before entering the exposure chamber. Size distribution and relative mass concentration $(133.73 \pm 1.87 \mathrm{~nm})$ of the aerosols were monitored in real time with a Scanning Mobility Particle Sizer (SMPS, TSI, Shoreview, MN). GD 4, 12, and 17 pregnant rats were placed in the 84-L whole-body exposure chamber for $5 \mathrm{~h}$ during a single inhalation exposure. Once a steady-state aerosol concentration was achieved, exposure duration was a single 4-h exposure at a final mass concentration of $9.71 \pm 0.22 \mathrm{mg} / \mathrm{m}^{3}$ to achieve a daily calculated pulmonary deposition of $15.8 \pm 1.2 \mu \mathrm{g}$. Animals were removed from the facility when concentrations with the chamber are below $1 \mathrm{mg} / \mathrm{m}^{3}$. All rats recovered for at least $24 \mathrm{~h}$ prior to experimental procedures. Sham animals were exposed to HEPA filtered air only. For the duration of the inhalation exposure, aerosol concentrations were verified using gravimetric sampling. Aerosols were collected on a 47-nm PTFE membrane filter and an XP2U microbalance (Mettler Toledo, Switzerland) was used to determine filter mass.

\section{Mean Arterial Pressure (MAP)}

Rats were anesthetized with isoflurane gas (5\% induction, 3-5\% maintenance). The right carotid artery was cannulated to acquire mean arterial pressure (MAP). A BLPR2 pressure transducer (World Precision Instruments, Sarasota, FL) was used in conjunction with a blood pressure monitor (World Precision Instruments, Sarasota, FL) to measure and record MAP.

\section{Wire Myography}

Wire myography (DMT-USA) was used to evaluate vascular reactivity in the maternal thoracic aorta, the uterine artery, the umbilical vein, and the fetal aorta (Fig. 1). Vessels were isolated, excised, and placed in cold physiological salt solution (PSS). Vessel segments $(2 \mathrm{~mm})$ were trimmed and transferred to a stainless-steel chamber, submerged in 6-mL chilled PSS (PSS; $130 \mathrm{mM} \mathrm{NaCl}, 4.7 \mathrm{mM} \mathrm{KCl}, 1.18 \mathrm{mM} \mathrm{KH}_{2} \mathrm{PO}_{4}$, $1.17 \mathrm{mM} \mathrm{MgSO}_{4} 7 \mathrm{H}_{2} \mathrm{O}, 1.6 \mathrm{mM} \mathrm{CaCl}_{2}, 14.9 \mathrm{mM} \mathrm{NaHCO}_{3}$, $0.026 \mathrm{mM}$ EDTA, and $5.5 \mathrm{mM}$ glucose), and mounted on two intraluminal stainless-steel wires $(0.04 \mathrm{~mm})$ in a multi-channel 
A

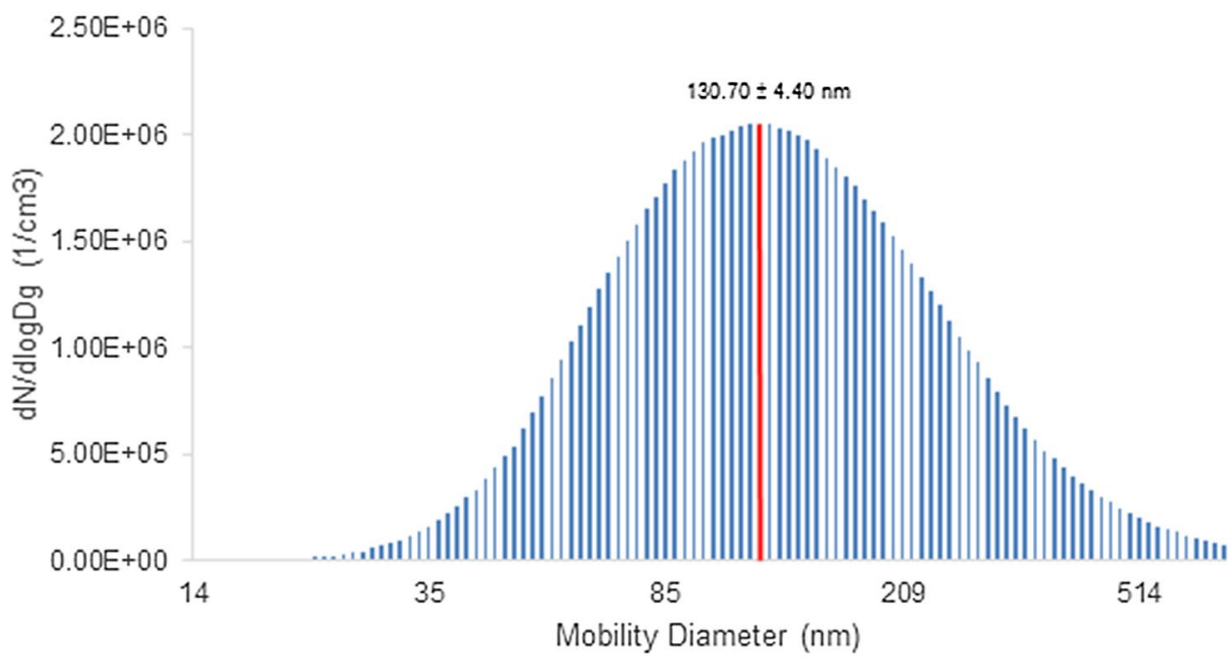

B

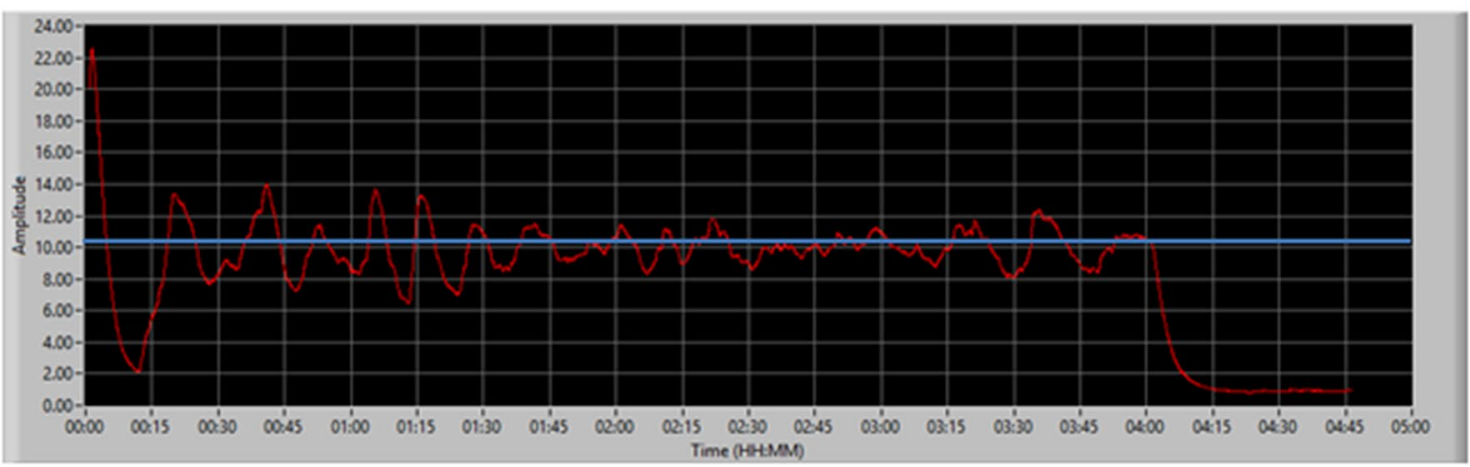

Facility Set Point: $10 \mathrm{mg} / \mathrm{m}^{3}$

Real Time Concentration: $9.44 \pm 0.26 \mathrm{mg} / \mathrm{m}^{3}$

Fig. 2 Exposure Characteristics. Real-time nano- $\mathrm{TiO}_{2}$ exposure characteristics. a Size-based aerodynamic diameter and mobility was characterized as $130.70 \pm 4.40 \mathrm{~nm}$. b A representative image of the

wire myograph (620M, DMT, Aarhus, Denmark). Once mounted, vessel chambers were heated slowly to $37{ }^{\circ} \mathrm{C}$ and bubbled gently with carbogen $\left(95 \% \mathrm{O}_{2} / 5 \% \mathrm{CO}_{2}\right)$. Following 20 min of equilibration, passive length-tension relationships were established for each vessel segment by stepwise stretching of the tissue rings. The optimum resting tension for each vessel segment was calculated based on the La of LaPlace $90 \%$ of the internal circumference established at tensions equivalent to $100 \mathrm{mmHg}$ (maternal aorta), $60 \mathrm{mmHg}$ (uterine artery), and $40 \mathrm{mmHg}$ (umbilical vein and fetal aorta). Once normalized, vessel segments were equilibrated for $40 \mathrm{~min}$ followed by a brief "wake-up" protocol in which maximum contractile response was determined using high-potassium PSS (KPSS; $74.7 \mathrm{mM} \mathrm{NaCl}, 60 \mathrm{mM} \mathrm{KCl}, 1.18 \mathrm{mM} \mathrm{KH}_{2} \mathrm{PO}_{4}$, $1.17 \mathrm{mM} \mathrm{MgSO}_{4} 7 \mathrm{H}_{2} \mathrm{O}, 1.6 \mathrm{mM} \mathrm{CaCl}_{2}, 14.9 \mathrm{mM} \mathrm{NaHCO}_{3}$, $0.026 \mathrm{mM}$ EDTA, and $5.5 \mathrm{mM}$ glucose). Vessels were then washed over a period of $20 \mathrm{~min}$ with PSS and allowed to relax real-time aerosol concentration of nano- $\mathrm{TiO}_{2}$ during the 4-h exposure, showing a maintained plateau at $9.44 \pm 0.26 \mathrm{mg} / \mathrm{m}^{3}$. Values are means $\pm \mathrm{SE}$

until initial tension was reached. Contractile responses were determined via cumulative additions of $60 \mu \mathrm{L}$ of phenylephrine (PHE; $1 \times 10^{-9}$ to $1 \times 10^{-4} \mathrm{M}$ ). Relaxation responses were evaluated via cumulative addition of $60 \mu \mathrm{L}$ methacholine $\left(\mathrm{MCH} ; 1 \times 10^{-9}\right.$ to $\left.1 \times 10^{-4} \mathrm{M}\right)$ or sodium nitroprusside (SNP; $1 \times 10^{-9}$ to $\left.1 \times 10^{-4} \mathrm{M}\right)$. Responses to chemical agents were randomized.

\section{Pharmacological Agents for Vascular Studies}

Phenylephrine (ACROS Organics, Geel, Belgium) was dissolved in PSS. Sodium nitroprusside (Thermo Fisher Scientific, Waltham, MA) was dissolved in PSS. Methacholine (MP Biomedicals LLC, Santa Ana, CA) was dissolved in PSS. 
Table 1 Animal characteristics

\begin{tabular}{lllllllll}
\hline Treatment & $\begin{array}{l}\text { Maternal } \\
\text { weight }(\mathrm{g})\end{array}$ & $\begin{array}{l}\text { Mean arterial } \\
\text { pressure }\end{array}$ & $\begin{array}{l}\text { Number } \\
\text { of rats } \\
(\mathrm{n})\end{array}$ & $\begin{array}{l}\text { Calculate } \\
\text { particle depo- } \\
\text { sition }\end{array}$ & $\begin{array}{l}\text { Number of } \\
\text { reabsorption } \\
\text { sites }\end{array}$ & $\begin{array}{l}\text { Number of } \\
\text { pups }\end{array}$ & $\begin{array}{l}\text { Pup weight (g) } \\
\text { Placenta weight } \\
(\mathrm{g})\end{array}$ \\
\hline Naive & $380.92 \pm 10.07$ & & 13.00 & 0 & $0.58 \pm 0.23$ & $13.08 \pm 0.40$ & $2.55 \pm 0.02$ & $0.43 \pm 0.01$ \\
Air 4 & $366.60 \pm 13.35$ & $95.00 \pm 2.77$ & 5.00 & 0 & $0.20 \pm 0.20$ & $10.40 \pm 2.44$ & $2.56 \pm 0.04$ & $0.42 \pm 0.01$ \\
Air 12 & $347.33 \pm 16.05$ & $93.20 \pm 2.54$ & 6.00 & 0 & $0.00 \pm 0.00$ & $11.67 \pm 1.65$ & $2.48 \pm 0.04$ & $0.42 \pm 0.01$ \\
Air 17 & $376.00 \pm 16.05$ & $92.75 \pm 7.36$ & 4.00 & 0 & $0.00 \pm 0.00$ & $12.50 \pm 3.50$ & $2.65 \pm 0.03$ & $0.45 \pm 0.01$ \\
ENM 4 & $364.17 \pm 11.78$ & $96.80 \pm 4.36$ & 6.00 & $12.30 \pm 0.34^{*}$ & $1.50 \pm 0.76(p=12.33 \pm 0.56$ & $2.50 \pm 0.03$ & $0.44 \pm 0.01(p=$ \\
& & & & & $0.15)$ & & $0.08)$ \\
ENM 12 & $360.88 \pm 11.43$ & $84.75 \pm 4.64$ & 8.00 & $13.64 \pm 0.37 *$ & $1.38 \pm 0.18^{*}$ & $11.71 \pm 0.64$ & $2.65 \pm 0.03 *+\ddagger$ & $0.48 \pm 0.01 * \dagger$ \\
ENM 17 & $378.71 \pm 16.37$ & $91.00 \pm 3.78$ & 7.00 & $15.79 \pm 0.43^{*}$ & $0.71 \pm 0.29 *$ & $12.14 \pm 0.67$ & $2.57 \pm 0.03$ & $0.49 \pm 0.01^{\dagger}$ \\
\hline
\end{tabular}

Values are shown as mean \pm SEM. Statistics were analyzed with a one-way analysis of variance $(p \leq 0.05)$

$n$ number of animals

${ }^{*} p \leq 0.05$ when compared with Air at each respective gestational day

${ }^{\dagger} p \leq 0.05$ when compared with ENM 4

${ }^{\ddagger} p \leq 0.05$ when compared with ENM 17
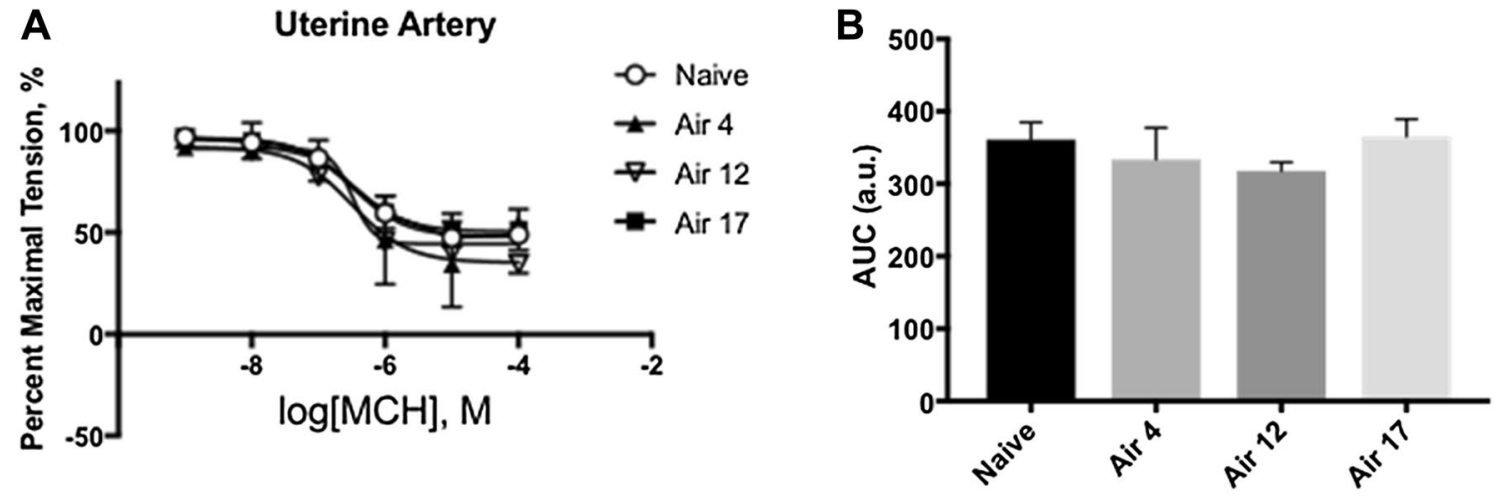

Fig. 3 Representative endothelium-dependent relaxation in the uterine artery following a single exposure to filtered air at gestational day 4,12 , and 17 compared with naïve hemodynamic control. Percentage of maximum tension (a) and area under the reactivity curve (b)

calculations are provided. No significant differences between groups. Therefore, we are confident pooling naïve and filtered air from different gestational day exposures (GD 4, 12, and 17) as representative "control"

\section{Wire Myography Calculations}

\section{Statistics}

Maximum tension was defined as the tension developed by the vessel segments with the addition of high-potassium PSS (KPSS; $74.7 \mathrm{mM} \mathrm{NaCl}, 60 \mathrm{mM} \mathrm{KCl}, 1.18 \mathrm{mM} \mathrm{KH}_{2} \mathrm{PO}_{4}$, $1.17 \mathrm{mM} \mathrm{MgSO}_{4} 7 \mathrm{H}_{2} \mathrm{O}, 1.6 \mathrm{mM} \mathrm{CaCl}_{2}, 14.9 \mathrm{mM} \mathrm{NaHCO}_{3}$, $0.026 \mathrm{mM}$ EDTA, and $5.5 \mathrm{mM}$ glucose). Tension at baseline and with agonists (MCH, SNP, or PHE) was recorded and the percentage of maximum tension generation was calculated using the following formula:

Percentage maximum tension $(\%)=[($ Tension with agonists $(\mathrm{mN})$

Point-to-point differences in the dose-response curves were evaluated using two-way repeated measures analysis of variance (ANOVA) with a Tukey's post hoc analysis when significance was found. The area under the concentration/dose response data of the concentration/dose response curves were determined through non-linear regression. All statistical analyses were completed with GraphPad Prism 7.0 (San Diego, CA, USA). All data are expressed as mean \pm SEM and significance is set at $p \leq 0.05$. 
A

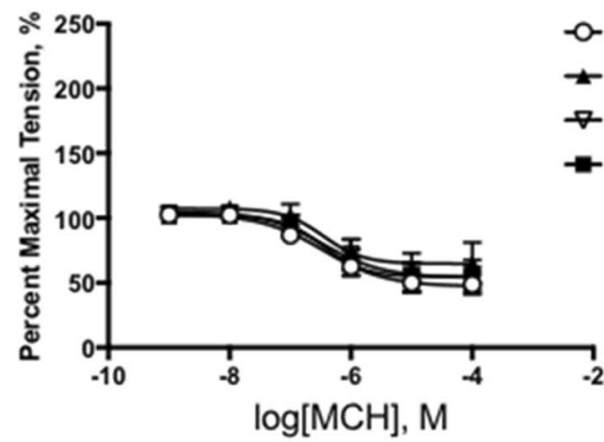

C

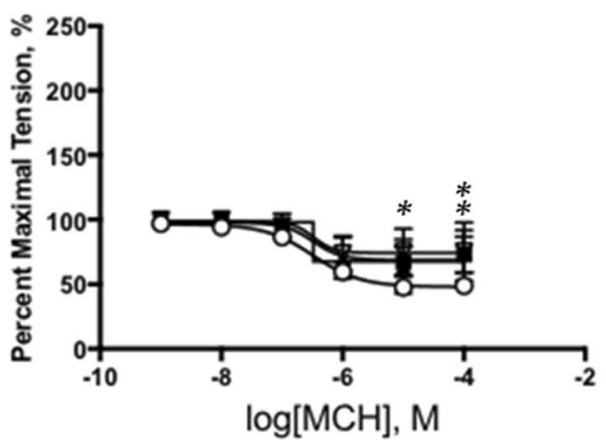

E

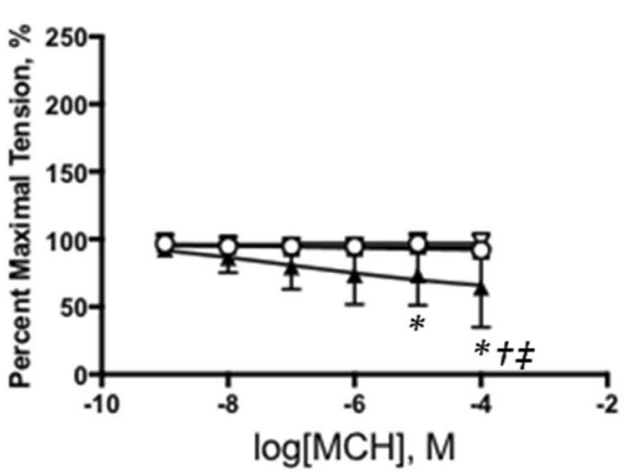

G

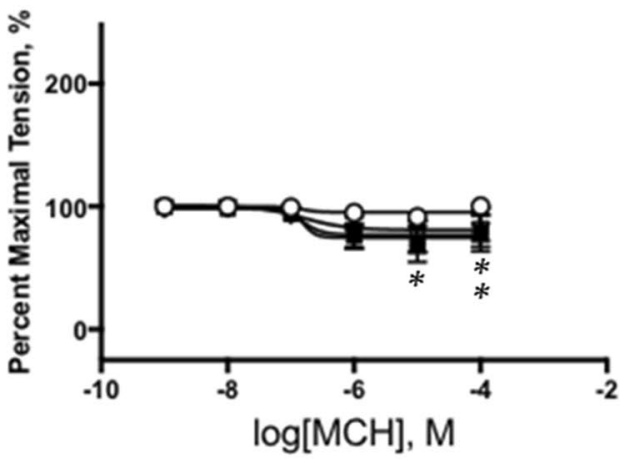

B

Maternal Aorta

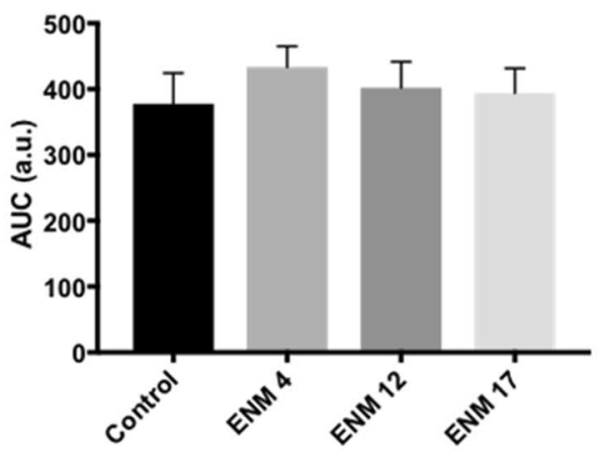

D

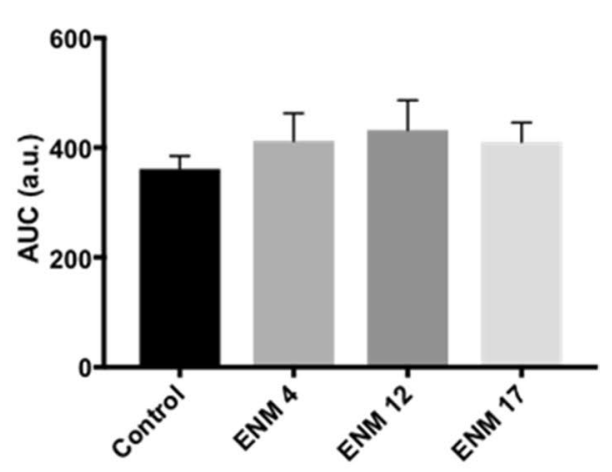

F

Umbilical Vein

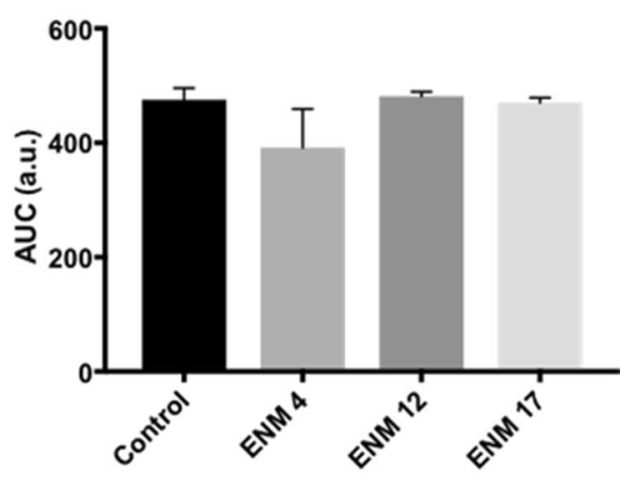

H

Fetal Aorta

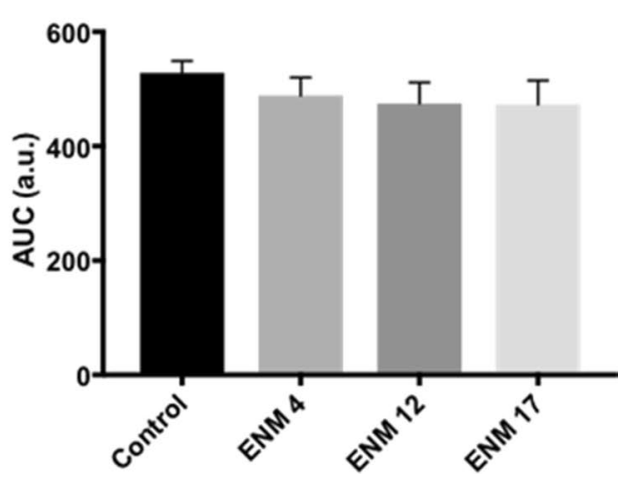


4Fig. 4 Changes in endothelium-dependent relaxation following a single exposure to aerosolized nano- $\mathrm{TiO}_{2}$ at gestational day 4,12 , and 17. The changes in the relaxation responses of segments of maternal and fetal vascular tissues at gestational day 20 in ENM-exposed and control Sprague Dawley rats in response to cumulative concentrations of methacholine $(\mathrm{MCH})$ are provided for maternal thoracic aorta (a), uterine artery (c), umbilical vein (e), and fetal aorta (g), compared with maximum tension generation in response to KPSS. Area under the curve calculations are provided to represent overall segment reactivity of the maternal thoracic aorta (b), uterine artery (d), umbilical vein (f), and fetal aorta (h) to the MCH dose-response. ${ }^{*} p \leq 0.05$ when compared with Control; ${ }^{\dagger} p \leq 0.05$ when compared with ENM $12 ;{ }^{\ddagger} p \leq 0.05$ when compared with ENM 17. $n=6-13$

\section{Results}

\section{$\mathrm{TiO}_{2}$ Nanoparticle Characterization}

Representative nano- $\mathrm{TiO}_{2}$ aerosol characterization data are presented in Fig. 2. The average median of our particle geometric size distribution was $130.70 \pm 4.40 \mathrm{~nm}$ (Fig. 2a). A representative image of the real-time nano- $\mathrm{TiO}_{2}$ concentration of $\left(9.44 \pm 0.26 \mathrm{mg} / \mathrm{m}^{3}\right)$ over the duration of the $4-\mathrm{h}$ whole-body exposure demonstrates the ability of our custom inhalation exposure system to provide stable distribution of nanoparticles for acute applications (Fig. 2b). The calculated lung depositions of nano- $\mathrm{TiO}_{2}$ aerosols with consideration for clearance are presented in Table 1.

\section{Maternal, Litter, and Fetal Characteristics}

Animal number, maternal body weight, MAP, number of reabsorption sites, litter size, pup weight, and placenta weight are reported in Table 1. At the time of the study, no statistically significant differences were observed between Naïve and Air groups. Further there were no statistically significant differences between groups with respect to maternal body weight, MAP, or litter size (Table 1). Number of reabsorption sites and placental weights were greater in animals exposed to $\mathrm{TiO}_{2}$ on GD 12 and 17 compared with animals exposed to filtered air on the equivalent GD. While the number of pups was not significantly different, those in the GD 12 exposure group were significantly larger than control, ENM 4, and ENM 17 counterparts.

\section{Vascular Responses in Naïve and Air Groups Following $\mathrm{Nano}^{-\mathrm{TiO}_{2}}$ Exposure}

There were no significant differences with respect to tension generation in response to PHE, or relaxation responses to MCH or SNP between Naïve and Air groups (data not shown). Data pertaining to endothelium-dependent function of the uterine artery are represented in Fig. 3a, b. Accordingly, cumulative response data for wire myograph investigations of vessel segments from Naïve and Air exposed groups were combined for simplification. When referencing the findings of the "control" group, we are referring to collective data from Naïve and Air groups.

\section{Changes in Vascular Responses Following Nano-TiO Exposure}

\section{Endothelium-Dependent Reactivity}

No differences were reported in endothelium-dependent responses in maternal aortic segments between ENM and control groups (Fig. 4a, b).

Maximum relaxation responses from peak force within uterine artery segments derived from ENM 12 and ENM 17 animal exposures were significantly higher than control. Wherein preconstricted control artery segments relaxed by $48.90 \pm 3.68 \%, 75.36 \pm 22.53 \%$ for ENM $4,75.29 \pm 16.42 \%$ $(p<0.05$ vs. control) for ENM 12, and $73.08 \pm 13.89 \%$; $(p<0.05$ vs. control) for ENM 17 (Fig. 4c). However, overall uterine artery reactivity to increased concentrations of $\mathrm{MCH}$ was not significantly different between groups (Fig. 4d).

Fetal umbilical vein segments from animals exposed to ENM at GD 4 demonstrated significant relaxation at the highest concentrations of $\mathrm{MCH}\left(10^{-5} \mathrm{M}-10^{-4} \mathrm{M}\right)$ compared with control and later gestational ENM exposures (Fig. 4e). Analysis of the total response indicates an inability of the fetal umbilical vein to relax to cumulative concentrations of MCH (Fig. 4f). Physiologically, this could lead to reduced perfusion or higher blood pressures entering the fetal compartment.

Analysis of fetal thoracic aortic reactivity to discrete concentrations of $\mathrm{MCH}$ yields significance at the highest concentrations of MCH $\left(10^{-5} \mathrm{M}-10^{-4} \mathrm{M}\right)$ (Fig. 4g). However, the overall relaxation response of fetal thoracic aortic segments to $\mathrm{MCH}$ was not different between ENM exposed and control (Fig. 4h).

\section{Endothelium-Independent Reactivity}

Endothelium-independent relaxation of the maternal aorta and the uterine artery, assessed in response to SNP, a spontaneous nitric oxide (NO) donor, after exposure to ENM at gestational day 4, 12, and 17 was consistent with responses from vessel segments in control animals suggesting a functional NO signaling cascade and subsequent smooth muscle relaxation (Fig. 5a-d).

Interestingly, point-by-point analysis revealed SNP induced significant concentration-dependent relaxation in umbilical vein segments following a single exposure at GD 4 (Fig. 5e). Umbilical vein segments derived from animals exposed to ENM on GD 4 were more responsive to SNP than either control or exposure groups at later gestational time 
A

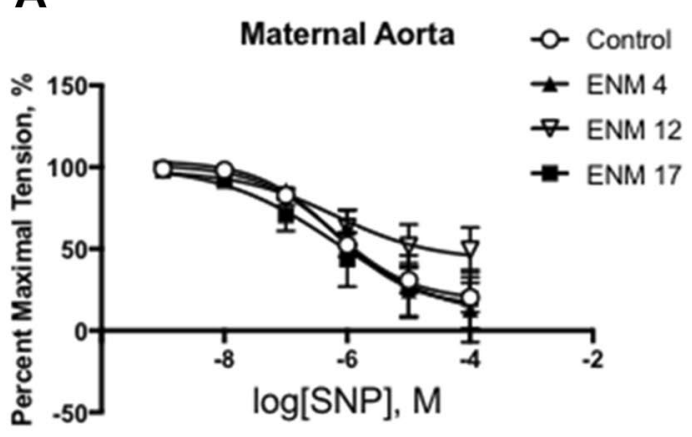

C

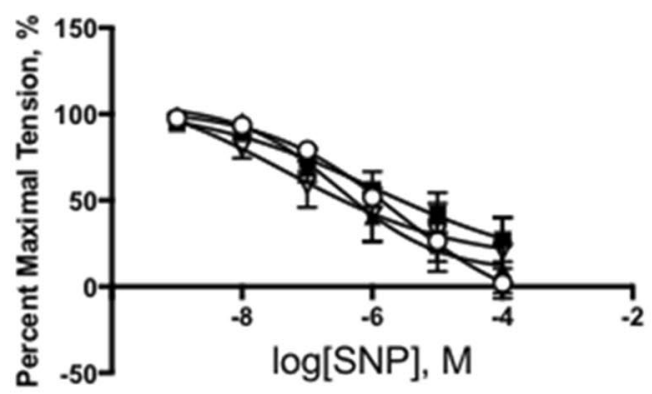

E

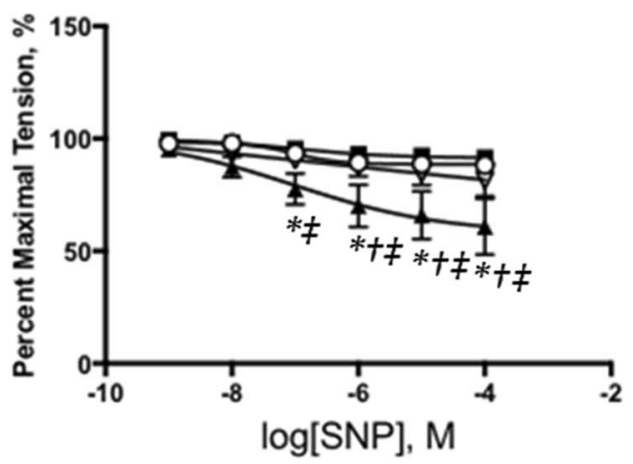

G

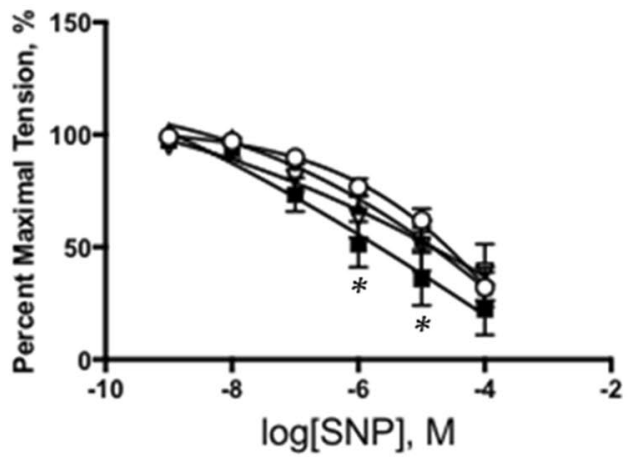

B

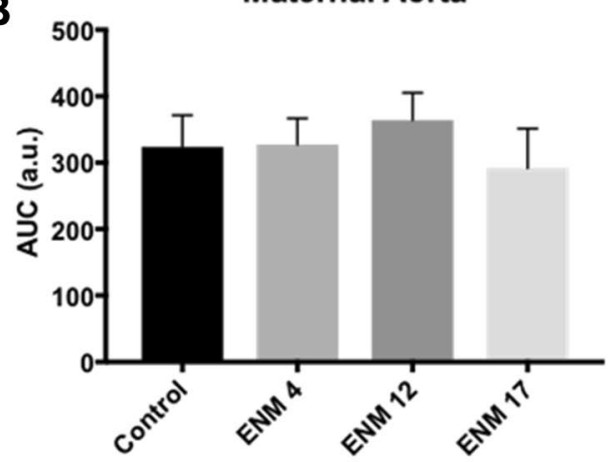

D

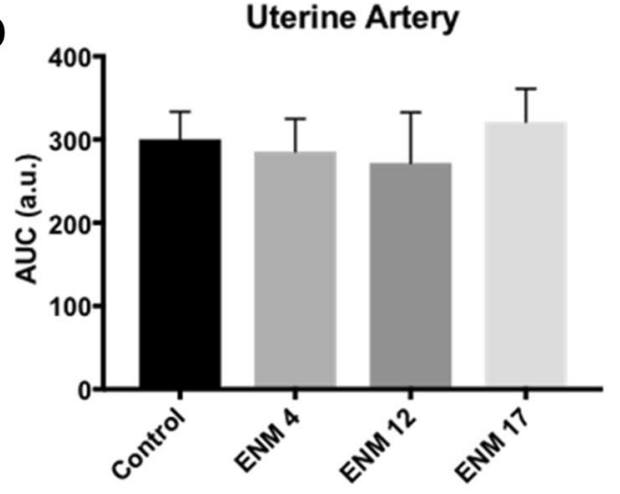

F

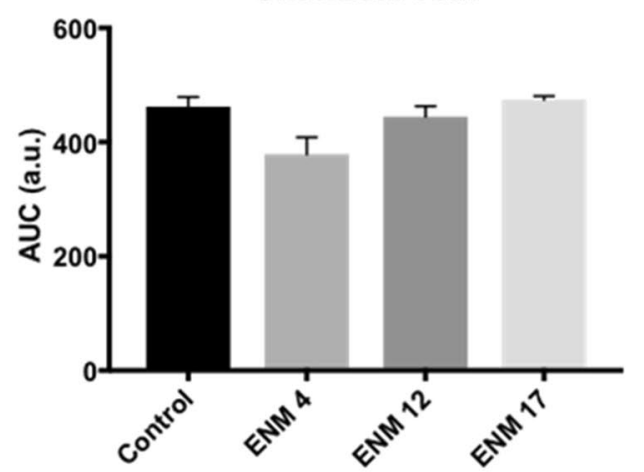

H

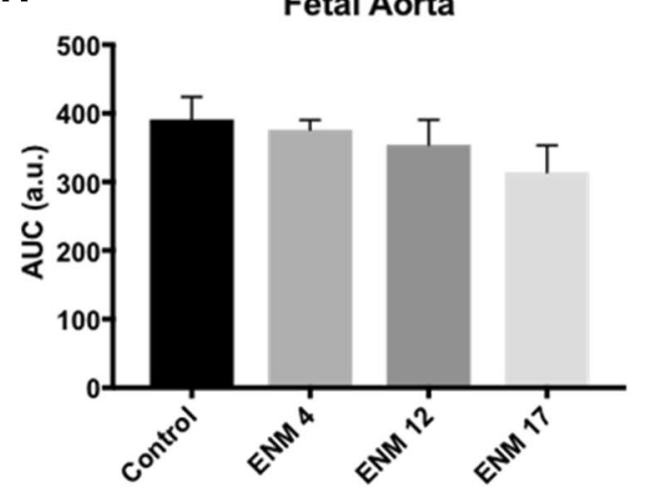


4Fig. 5 Changes in endothelium-independent relaxation following a single exposure to aerosolized nano- $\mathrm{TiO}_{2}$ at gestational day 4,12 , and 17. The changes in the relaxation responses of segments of maternal and fetal vascular tissues at gestational day 20 in ENM-exposed and control Sprague Dawley rats. Reactivity in response to cumulative concentrations of sodium nitroprusside (SNP) compared with maximum tension generation in response to KPSS is provided for maternal thoracic aorta (a), uterine artery (c), umbilical vein (e), and fetal aorta (g). Area under the curve calculations are provided to represent overall segment reactivity of the maternal thoracic aorta (b), uterine artery (d), umbilical vein (f), and fetal aorta (h) to the SNP doseresponse. ${ }^{*} p \leq 0.05$ when compared with Control; ${ }^{\dagger} p \leq 0.05$ when compared with ENM $12 ;{ }^{\ddagger} p \leq 0.05$ when compared with ENM 17. $n=6-13$

points, indicated by a reduced area under the curve calculation; however, this value did not reach significance (Fig. 5f).

Umbilical Vein sensitivity to SNP was unaffected by single ENM exposure early in gestation (Fig. $5 \mathrm{~g}$ ). Endothelium-independent relaxation in response to SNP induced a significant relaxation in fetal thoracic aortic segments in ENM 17 at physiologically relevant concentrations $\left(10^{-6} \mathrm{M}-10^{-5} \mathrm{M}\right)$. There was a trend toward an increase in sensitivity to SNP as assessed by area under the concentration response curve in ENM exposure from early to late gestation, but this did not reach statistical significance (Fig. 5h).

\section{Smooth Muscle Contractility}

Vascular smooth muscle contractility was assessed in response to the selective $\alpha$-adrenergic receptor agonist PHE. Percent maximal tension generation in maternal aortic segments from animals exposed to nano- $\mathrm{TiO}_{2}$ on GD 17 was reduced by $24.0 \%$ in response to PHE when compared with control segments (Fig. 6a). However, sensitivity to PHE in animals exposed late in gestation (GD 17) was not significantly reduced overall when compared with control and animals exposed earlier in gestation. (Fig. 6b).

Smooth muscle contractility to maximal concentrations of PHE $\left(10^{-5} \mathrm{M}-10^{-4} \mathrm{M}\right)$ was significantly diminished in uterine artery segments from ENM $12(90.63 \pm 31.27 \%)$ and ENM 17 (45.06 $\pm 28.85 \%$ ) (Fig. 6c). However, these differences were not reflected in the overall hemodynamic responsiveness (Fig. 6d).

Significant differences were identified in the $\alpha$-adrenergic contractility of the umbilical vein after maternal ENM inhalation on GD 12 of pregnancy. This was identified through a reduced contraction at supraphysiological concentrations $\left(10^{-5} \mathrm{M}\right)$ (Fig. 6e).

$\alpha$-adrenergic contractility to PHE $\left(10^{-} 4 \mathrm{M}\right)$ was markedly increased in fetal thoracic aortic segments from ENM 12 $(68.92 \pm 24.73 \%)$ and ENM $17(88.94 \pm 28.61 \%)$ compared with control $(1.93 \pm 3.93 \%)$ (Fig. $6 \mathrm{~g})$. There was a trend toward an increase in sensitivity to PHE in fetal thoracic segments as assessed by area under the concentration response curve for ENM-exposed animals from early to late gestation, but due to variability within the responses, this did not reach significance ( $p=0.8,0.15,0.068$ compared with control for ENM 4, 12, 17, respectively) (Fig. 6h).

\section{Discussion}

For this study, we assessed vascular reactivity in vessel segments from maternal, uterine, and fetoplacental circulations at vulnerable life stages. Alterations to vascular reactivity were identified on GD 20 after maternal exposure on GD 4, 12 , and 17 . Together, a single maternal exposure on GD 4 led to modification of vascular reactivity in each functional compartment (e.g., endothelium-dependent, -independent, and smooth muscle). Further, these variations were identified through serial assessments of the maternofetal circulation, with the greatest impairments identified in vascular smooth muscle reactivity, initiated through $\alpha$-adrenergic signaling. Interestingly, fetal umbilical vein and fetal aorta reactivity were primarily modified in exposures initiated at GD 4. It is important to clarify that these single exposures took place 3,8 , and 16 days prior to assessment. Previous temporal studies of a non-pregnant occupational model identified epicardial arteriolar dysfunction for 7 days after multi-walled carbon nanotube inhalation [13]. Through these studies, we identified that a single maternal ENM inhalation exposure, even early in gestation, can have profound and long-lasting effects in maternal and fetal hemodynamic control.

Endothelium-dependent relaxation was assessed by generating cumulative concentration-response curves to $\mathrm{MCH}$, following preconstriction with PHE. Reduced cholinergic activity was reported for uterine artery from animals exposed to ENM at early, mid, and late gestation. Earlier investigations by our group reported significantly blunted endothelium-dependent relaxation in isolated fetal tail arterioles following maternal exposure to nano- $\mathrm{TiO}_{2}$ aerosols [16]. Collectively, these findings in combination with our published work confirm maternal exposure to ENM during gestation impairs fetal systemic cardiovascular function. Of note, we reported poor agonist stimulated relaxation of vascular segments from umbilical vein and thoracic fetal aorta. These observations are consistent with existing literature [23] and indicate that cholinergic responses may not be the primary signaling pathway for endothelium-dependent dilation within the umbilical vein or fetal aorta. Poor reactivity may be due to reduced cholinergic receptor populations in these understudied tissue beds, reduction in NO production or bioavailability, or reliance on compensatory signaling mechanisms. Further assessments should consider alternate pharmacological agents to assess the contribution of nitric oxide production or the generation of metabolites of 

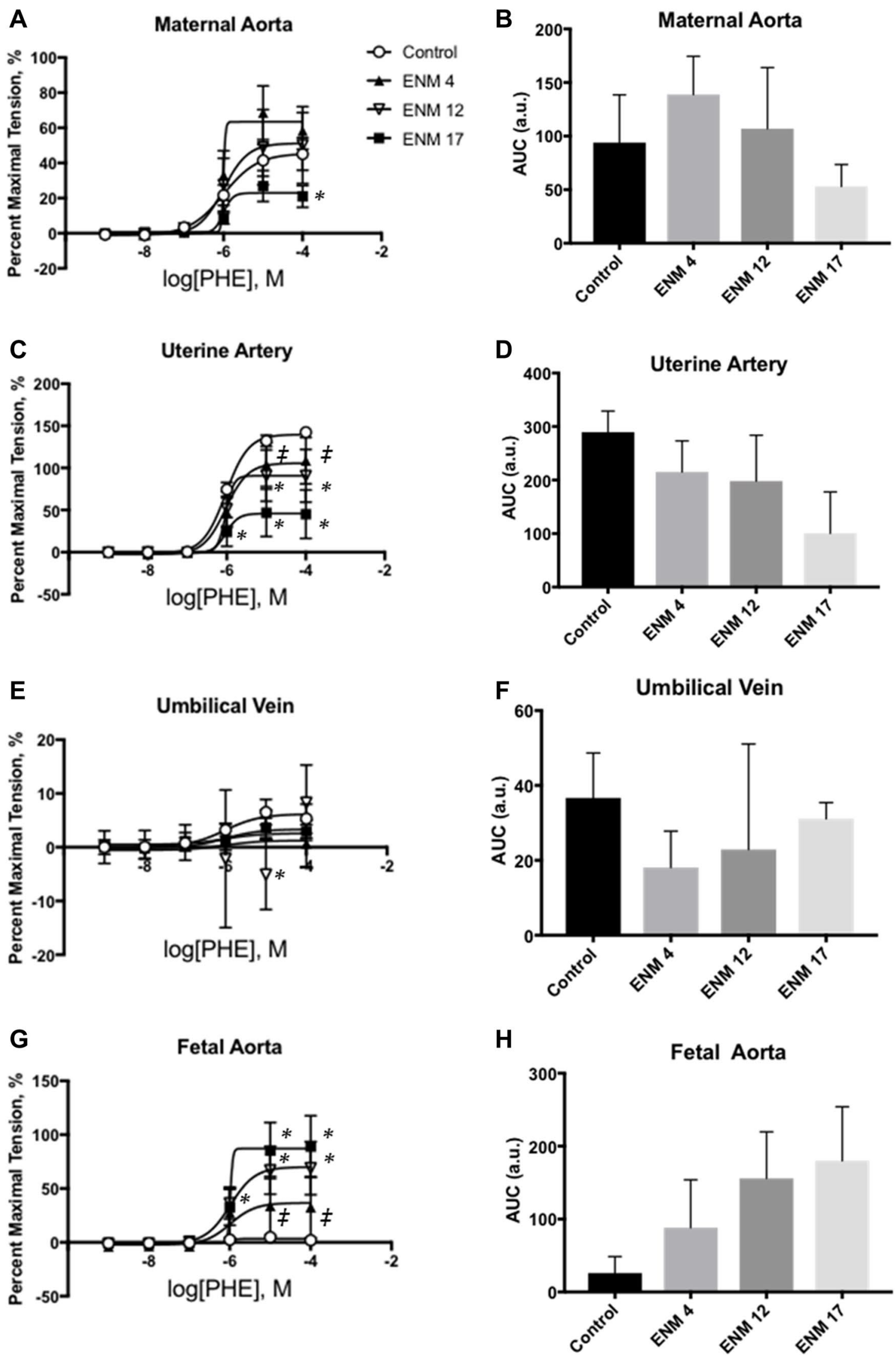
4Fig. 6 Changes in vascular smooth muscle contractility following a single exposure to aerosolized nano- $\mathrm{TiO}_{2}$ at gestational day 4,12 , and 17. The changes in tension generation of segments of maternal and fetal vascular tissues at gestational day 20 in ENM-exposed and control Sprague Dawley rats in response to cumulative concentrations of phenylephrine (PHE) are provided for maternal thoracic aorta (a), uterine artery (c), umbilical vein (e), and fetal aorta (g). Percent of maximal tension compared with KPSS responses is reported. Area under the curve calculations are provided to represent overall segment reactivity of the maternal thoracic aorta $(\mathbf{b})$, uterine artery $(\mathbf{d})$, umbilical vein (f), and fetal aorta (h) to the SNP dose-response. ${ }^{*} p \leq 0.05$ when compared with Control; ${ }^{\dagger} p \leq 0.05$ when compared with ENM 12 ; ${ }^{\ddagger} p \leq 0.05$ when compared with ENM 17. $n$, number of animals. $n=6-13$

arachidonic acid (e.g., the nitric oxide synthase inhibitor $\mathrm{L}-\mathrm{N}^{\mathrm{G}}$-nitroarginine methyl ester and the cyclooxygenase antagonist indomethacin). In addition, future assessments may include examining the response to physiological modifications, including changes in shear stress and transmural pressure to further evaluate endothelial health.

Interestingly, fetal tissues derived after ENM 4 and ENM 17 exposures demonstrated an improved relaxation to NO indicating the possibility of increased NO-sensitivity after early/late gestation maternal ENM inhalation. These responses would further emphasize the consideration of alternate EDHF agonists in future work. The local production of reactive oxygen species has also been implicated in the development of contractile and bioenergetic dysfunction and impairments in endothelium-dependent vasoreactivity associated with exposure to nano- $\mathrm{TiO}_{2}[24,25]$. Accordingly, incubation with 2,2,6,6-tetramethylpiperidine- $N$-oxyl, a superoxide dismutase mimetic, and catalase, a hydrogen peroxide scavenger, would help to determine the influence of local reactive oxygen species production associated with nano- $\mathrm{TiO}_{2}$ exposure during pregnancy. Smooth muscle contractility was assessed in response to the selective $\alpha$-adrenergic agonist, PHE. We observed that a single exposure to nano- $\mathrm{TiO}_{2}$ at mid (GD 12) and late (GD 17) gestation decreased maximum developed tension in the uterine artery. In contrast, smooth muscle contractility in the thoracic fetal aorta was significantly augmented in response to ENM exposure, an observation that was consistent at early, mid, and late gestation. Further, in ring segments from umbilical veins, contraction to $10^{-2} \mathrm{M}$ PHE was poor and variable. This observation is consistent with previous reports of agonist-induced contractile activity of murine umbilical arteries and veins [23]. In accordance with existing literature, exposure of umbilical vein segments to KPSS induced a maintained contraction. When compared with KPSS-induced contraction of uterine arteries, umbilical veins showed a significant decrease in maximal tension generation; similar findings have been reported in humans [26]. In isolated human umbilical vein rings, adrenaline was more potent than phenylephrine, $16 \%$ of the vessel rings did not demonstrate adrenergic responses to adrenaline or phenylephrine [27].

We observed differential responses between aortic, uterine, umbilical, and fetal aortic vessel segments with exposure to nano- $\mathrm{TiO}_{2}$ at multiple days across gestation. However, we have previously focused on the microcirculatory level of the vasculature $[14,16]$. Given this context, our current work aligns with the findings of existing studies of serial vascular assessment [28], that while macrocirculatory reactivity is blunted, the greatest impairments are identified in the microcirculation. Overall, we postulate heterogeneous responses in vascular reactivity may be related to differences in cholinergic and $\alpha$-adrenergic receptor populations and/or reliance on compensatory mechanism signaling cascades. This may include a shift in the role of arachidonic acid metabolites in the regulation of vascular tone (i.e., a disturbance in the ratio of the vascular smooth muscle dilator prostacyclin and the potent vasoconstrictor thromboxane $\mathrm{A}_{2}$ ) and/or increased reliance on Rho-kinase signaling [20, 22] after maternal ENM exposure.

Vascular remodeling during pregnancy, the time and pattern of which is specific to vessel size and location, is carefully orchestrated [29]. Pregnancy is accompanied by a progressive rise in uteroplacental blood flow (UPBF) in order to satisfy gestational demands of the developing fetus [1]. In rats, changes in total uterine blood flow are detected on or around the final third of gestation ( GD 15) [30]. Increases in total UPBF are facilitated by a combination of circulatory adaptations including a rise in cardiac output and an expanded intravascular volume. Under normal circumstances, MAP decreases slightly or remains unchanged. Consistent with normal pregnancy, we observed no significant differences in MAP between naïve, sham control, and ENM-exposed groups. Accordingly, changes in cardiac output are accompanied by a reciprocal decrease in vascular resistance. Together, vessel-specific structural remodeling and a shift in uterine vascular reactivity (reduced vessel tone and enhanced vasodilation) determine pregnancy-related changes in UPBF [1]. Future studies may explore the influence of known pregnancy-related changes in the vascular micro-environment on vascular reactivity in pregnancy.

Technological advancements in nanomaterial science afford an abundance of opportunities for innovation. Nanotechnology has led to achievements in the accuracy and effectiveness of medical diagnostic equipment, vehicle fuel efficiency, sources of renewable energy, environmental remediation, and therapeutic efficiency of pharmaceuticals. While the unique physiochemical properties of engineered nanomaterials incite a wealth of enthusiasm, the pervasive impact of this technology also begets concerns that development may be outpacing our understanding of its safety. Exposure of the maternal environment to ENM during pregnancy has been shown to impact health of the dam, 
fetus, and adult offspring [31]; however, the consequences of specific temporal (gestational day) and spatial (vascular location) considerations are largely undetermined. In this respect, the current study is the first to examine how exposure to nano- $\mathrm{TiO}_{2}$ at critical periods of gestation affects vascular responses during pregnancy, and whether the resulting changes differentially affect regionally discrete blood vessels of maternal and fetal circulations.

In summary, the findings of this study suggest moderate vascular dysfunction associated with a single maternal exposure to nano- $\mathrm{TiO}_{2}$ aerosols. These results provide evidence that exposure early in gestation (GD 4) will have a significant impact on fetal systemic vascular function.

Acknowledgements We thank Jane Salmon for her assistance in the preparation of Fig. 1., Vincent Lam, Rachel Suss, and Maria Chaves for their technical support, and Jeanine D'Errico for her review of the manuscript. This work was supported by the National Institute of Environmental Health Sciences (R00-ES024783), Rutgers Center for Environmental Exposures and Disease (P30-ES005022), and The Summer Undergraduate Research Fellowship Program (American Society for Pharmacology and Experimental Therapeutics and R25ES020721).

Open Access This article is distributed under the terms of the Creative Commons Attribution 4.0 International License (http://creativeco mmons.org/licenses/by/4.0/), which permits unrestricted use, distribution, and reproduction in any medium, provided you give appropriate credit to the original author(s) and the source, provide a link to the Creative Commons license, and indicate if changes were made.

\section{References}

1. Osol, G., \& Mandala, M. (2009). Maternal uterine vascular remodeling during pregnancy. Physiology, 24, 58-71.

2. Robichaud, C. O., Uyar, A. E., Darby, M. R., Zucker, L. G., \& Wiesner, M. R. (2009). Estimates of upper bounds and trends in nano-TiO2 production as a basis for exposure assessment. Environmental Science \& Technology, 43, 4227-4233.

3. LeBlanc, A. J., Cumpston, J. L., Chen, B. T., Frazer, D., Castranova, V., \& Nurkiewicz, T. R. (2009). Nanoparticle inhalation impairs endothelium-dependent vasodilation in subepicardial arterioles. Journal of Toxicology and Environmental Health, Part A, $72,1576-1584$.

4. Nurkiewicz, T. R., Porter, D. W., Hubbs, A. F., Stone, S., Moseley, A. M., Cumpston, J. L., Goodwill, A. G., Frisbee, S. J., Perrotta, P. L., Brock, R. W., Frisbee, J. C., Boegehold, M. A., Frazer, D. G., Chen, B. T., \& Castranova, V. (2011). Pulmonary particulate matter and systemic microvascular dysfunction. Research Report 164, 3-48.

5. Roberts, J. R., McKinney, W., Kan, H., Krajnak, K., Frazer, D. G., Thomas, T. A., Waugh, S., Kenyon, A., MacCuspie, R. I., Hackley, V. A., \& Castranova, V. (2013). Pulmonary and cardiovascular responses of rats to inhalation of silver nanoparticles. Journal of Toxicology and Environmental Health, Part A, 76, 651-668.

6. Saber, A. T., Lamson, J. S., Jacobsen, N. R., Ravn-Haren, G., Hougaard, K. S., Nyendi, A. N., Wahlberg, P., Madsen, A. M., Jackson, P., Wallin, H., \& Vogel, U. (2013). Particle-induced pulmonary acute phase response correlates with neutrophil influx linking inhaled particles and cardiovascular risk. PLOS ONE, 8, e69020.
7. Knuckles, T. L., Yi, J., Frazer, D. G., Leonard, H. D., Chen, B. T., Castranova, V., \& Nurkiewicz, T. R. (2012). Nanoparticle inhalation alters systemic arteriolar vasoreactivity through sympathetic and cyclooxygenase-mediated pathways. Nanotoxicology, 6 , 724-735.

8. McKinney, W., Jackson, M., Sager, T. M., Reynolds, J. S., Chen, B. T., Afshari, A., Krajnak, K., Waugh, S., Johnson, C., Mercer, R. R., Frazer, D. G., Thomas, T. A., \& Castranova, V. (2012). Pulmonary and cardiovascular responses of rats to inhalation of a commercial antimicrobial spray containing titanium dioxide nanoparticles. Inhalation Toxicology, 24, 447-457.

9. Mills, N. L., Miller, M. R., Lucking, A. J., Beveridge, J., Flint, L., Boere, A. J., Fokkens, P. H., Boon, N. A., Sandstrom, T., Blomberg, A., Duffin, R., Donaldson, K., Hadoke, P. W., Cassee, F. R., \& Newby, D. E. (2011). Combustion-derived nanoparticulate induces the adverse vascular effects of diesel exhaust inhalation. European Heart Journal, 32, 2660-2671.

10. Wingard, C. J., Walters, D. M., Cathey, B. L., Hilderbrand, S. C., Katwa, P., Lin, S., Ke, P. C., Podila, R., Rao, A., Lust, R. M., \& Brown, J. M. (2011). Mast cells contribute to altered vascular reactivity and ischemia-reperfusion injury following cerium oxide nanoparticle instillation. Nanotoxicology, 5, 531-545.

11. Stampfl, A., Maier, M., Radykewicz, R., Reitmeir, P., Gottlicher, M., \& Niessner, R. (2011). Langendorff heart: A model system to study cardiovascular effects of engineered nanoparticles. ACS Nano, 5, 5345-5353.

12. Oesterling, E., Chopra, N., Gavalas, V., Arzuaga, X., Lim, E. J., Sultana, R., Butterfield, D. A., Bachas, L., \& Hennig, B. (2008). Alumina nanoparticles induce expression of endothelial cell adhesion molecules. Toxicology Letter, 178, 160-166.

13. Stapleton, P. A., Minarchick, V. C., Cumpston, A. M., McKinney, W., Chen, B. T., Sager, T. M., Frazer, D. G., Mercer, R. R., Scabilloni, J., Andrew, M. E., Castranova, V., \& Nurkiewicz, T. R. (2012). Impairment of coronary arteriolar endotheliumdependent dilation after multi-walled carbon nanotube inhalation: A time-course study. International Journal of Molecular Sciences, 13, 13781-13803.

14. Stapleton, P. A., McBride, C. R., Yi, J., Abukabda, A. B., \& Nurkiewicz, T. R. (2018). Estrous cycle-dependent modulation of in vivo microvascular dysfunction after nanomaterial inhalation. Reproduction Toxicology, 78, 20-28.

15. Witschi, E. (1962). Development: Rat.

16. Stapleton, P. A., Minarchick, V. C., Yi, J., Engels, K., McBride, C. R., \& Nurkiewicz, T. R. (2013). Maternal engineered nanomaterial exposure and fetal microvascular function: Does the Barker hypothesis apply? American Journal of Obstetrices Gynecology, 209, e221-e211.

17. Blum, J. L., Xiong, J. Q., Hoffman, C., \& Zelikoff, J. T. (2012). Cadmium associated with inhaled cadmium oxide nanoparticles impacts fetal and neonatal development and growth. Toxicological Sciences, 126, 478

18. Blum, J. L., Chen, L. C., \& Zelikoff, J. T. (2017). Exposure to ambient particulate matter during specific gestational periods produces adverse obstetric consequences in mice. Environmental Health Perspectives, 125, 077020.

19. Blum, J. L., Edwards, J. R., Prozialeck, W. C., Xiong, J. Q., \& Zelikoff, J. T. (2015). Effects of maternal exposure to cadmium oxide nanoparticles during pregnancy on maternal and offspring kidney injury markers using a murine model. Journal Toxicology Environmental Health Part A, 78, 711-724.

20. Vidanapathirana, A. K., Thompson, L. C., Mann, E. E., Odom, J. T., Holland, N. A., Sumner, S. J., Han, L., Lewin, A. H., Fennell, T. R., Brown, J. M., \& Wingard, C. J. (2014). PVP formulated fullerene (C60) increases Rho-kinase dependent vascular tissue contractility in pregnant Sprague Dawley rats. Reproductive Toxicology, 49, 86-100. 
21. Vidanapathirana, A. K., Thompson, L. C., Herco, M., Odom, J., Sumner, S. J., Fennell, T. R., Brown, J. M., \& Wingard, C. J. (2018). Acute intravenous exposure to silver nanoparticles during pregnancy induces particle size and vehicle dependent changes in vascular tissue contractility in Sprague Dawley rats. Reproductive Toxicology, 75, 10-22.

22. Vidanapathirana, A. K., Thompson, L. C., Odom, J., Holland, N. A., Sumner, S. J., Fennell, T. R., Brown, J. M., \& Wingard, C. J. (2014). Vascular tissue contractility changes following late gestational exposure to multi-walled carbon nanotubes or their dispersing vehicle in sprague dawley rats. Journal of Nanomedical Nanotechnology, 5, 3 .

23. Kusinski, L. C., Baker, P. N., Sibley, C. P., \& Wareing, M. (2009). In vitro assessment of mouse uterine and fetoplacental vascular function. Reproductive Sciences, 16, 740-748.

24. Nichols, C. E., Shepherd, D. L., Hathaway, Q. A., Durr, A. J., Thapa, D., Abukabda, A., Yi, J., Nurkiewicz, T. R., \& Hollander, J. M. (2018). Reactive oxygen species damage drives cardiac and mitochondrial dysfunction following acute nanotitanium dioxide inhalation exposure. Nanotoxicology, 12, 32-48.

25. LeBlanc, A. J., Moseley, A. M., Chen, B. T., Frazer, D., Castranova, V., \& Nurkiewicz, T. R. (2010). Nanoparticle inhalation impairs coronary microvascular reactivity via a local reactive oxygen species-dependent mechanism. Cardiovascular Toxicology, $10,27-36$.

26. Takeji, T., Nakaya, Y., Kamada, M., Maeda, K., Saijo, Y., Mitani, R., Irahara, M., \& Aono, T. (2000). Effect of a novel vasoconstrictor endothelin-1 (1-31) on human umbilical artery. Biochemical Biophysical Research Communication, 270, 622-624.
27. Errasti, A. E., Velo, M. P., Torres, R. M., Sardi, S. P., \& Rothlin, R. P. (1999). Characterization of alpha1-adrenoceptor subtypes mediating vasoconstriction in human umbilical vein. British Journal of Pharmacology, 126, 437-442.

28. Abukabda, A. B., Stapleton, P. A., McBride, C. R., Yi, J., \& Nurkiewicz, T. R. (2017). Heterogeneous vascular bed responses to pulmonary titanium dioxide nanoparticle exposure. Front Cardiovascular Medicine, 4, 33.

29. Osol, G., \& Moore, L. G. (2014). Maternal uterine vascular remodeling during pregnancy. Microcirculation, 21, 38-47.

30. Dowell, R. T., \& Kauer, C. D. (1997). Maternal hemodynamics and uteroplacental blood flow throughout gestation in conscious rats. Methods and Findings in Experimental and Clinical Pharmacology, 19, 613-625.

31. Hougaard, K. S., Campagnolo, L., Chavatte-Palmer, P., Tarrade, A., Rousseau-Ralliard, D., Valentino, S., Park, M. V., de Jong, W. H., Wolterink, G., Piersma, A. H., Ross, B. L., Hutchison, G. R., Hansen, J. S., Vogel, U., Jackson, P., Slama, R., Pietroiusti, A., \& Cassee, F. R. (2015). A perspective on the developmental toxicity of inhaled nanoparticles. Reproductive Toxicology, 56, 118-140.

Publisher's Note Springer Nature remains neutral with regard to jurisdictional claims in published maps and institutional affiliations. 